\title{
Phenotypic plasticity, seasonal climate and the population biology of Bicyclus butterflies (Satyridae) in Malawi
}

\section{PAUL M. BRAKEFIELD and NICO REITSMA}

Section of Evolutionary Biology, Department of Population Biology, University of Leiden, The Netherlands

Abstract. 1. Seasonal polyphenism is studied in a community of five African butterflies of the genus Bicyclus at the transition between a wet and a dry season from May to July.

2. Butterflies characterized by large eyespots and, especially in B.safitza (Hewitson), a pale band (the wet season form) are replaced over this period by butterflies lacking conspicuous wing markings (the dry season form, dsf). The latter butterflies also tend to be larger, but more variable in size. Butterflies of an intermediate phenotype are recruited over a comparatively short interim period.

3. This turnover coincides with a period of declining temperature and drying of the habitat, including the grasses on which larvae feed. Butterflies are progressively more likely to rest on brown leaf litter rather than on green herbage.

4. A relationship with temperature is supported by laboratory experiments with B.safitza and B.anynana (Butler) showing that increasingly extreme dsf butterflies develop with decreasing rearing temperature in the final larval instar.

5. Some differences in behaviour and activity were observed between the seasonal forms. Butterflies of the dsf develop ovarian dormancy and fat bodies. They can survive to reproduce at the beginning of the rains in November.

6. Capture-recapture experiments showed that the adult butterflies have a comparatively long life expectancy and are quite sedentary.

7. The results are discussed in relation to a hypothesis linking the polyphenism to seasonal changes in resting background and selection for crypsis.

Key words. Phenotypic plasticity, seasonal polyphenism, Bicyclus, crypsis, butterfly, Malawi, wing pattern, climate, mortality.

Correspondence: Professor P. M. Brakefield and Dr N. Reitsma, Section of Evolutionary Biology, Department of Population Biology, University of Leiden, Schelpenkade 14a, 2313 ZT Leiden, The Netherlands. 


\section{Introduction}

In tropical regions with alternating wet and dry seasons, organisms are confronted with periodical, more or less radical changes in their ecological environment. Many insects migrate in space or time (diapause) to escape the dry season environment (e.g. Dingle, 1982; Wolda, 1988; Gatehouse, 1989). An alternative is found in some herbivorous insects, including species of satyrine butterflies, which show phenotypic plasticity and have different forms in each season (Shapiro, 1976; Brakefield \& Larsen, 1984). In the tropical satyrines, adults can remain active, or potentially active, throughout the year (although they may show reproductive diapause in the dry season; see Brakefield, 1987). This enables opportunistic use of adult food resources in the long dry season and probably a more rapid breeding response to the onset of rains than is possible with strict diapause at some earlier developmental stage (see Slansky, 1982).

The seasonal forms of some species of Bicyclus and other satyrines exhibit striking differences in their ventral wing pattern (Brakefield \& Larsen, 1984). The wet season form is characterized by submarginal eyespots and, in some species, a pale band. These patterns are conspicuous when the butterflies are at rest on leaf litter or low herbage. The dry season form lacks eyespots and a band and has a more or less uniform brown colour. Butterflies with intermediate phenotype may also occur. The type of phenotypic changes involved in this example of seasonal polyphenism have been quantified for an old series of Melanitis leda collected on Mauritius (Brakefield, 1987). The changes were correlated with variation in ambient temperature.

Seasonal biotopes in Africa are characterized by a luxuriant layer of green herbage in the rains which dies away to dead leaves or bare ground in the dry season. Such changes may favour crypsis and the absence of conspicuous pattern elements in the dry season when the satyrine butterflies rest inactively on the dead leaves while the wet season butterflies, which are active and rest intermittently on the green herbage, may use eyespots and bands as active anti-predator devices (Owen, 1980; Brakefield \& Larsen, 1984). We studied aspects of the population biology of species of Bicyclus in Malawi at the transition between a wet and a dry season to examine this hypothiesis about selection. The turnover within populations over this period was studiẹd together with changes in reproductive state, behaviour and activity. Laboratory experiments were used to examine the environmental control of the phenotypic plasticity.

\section{Material and Methods}

Study areas. The study areas are about $60 \mathrm{~km}$ apart, at Zomba and Blantyre in Malawi (15$\left.16^{\circ} \mathrm{S}\right)$. They are at about $900 \mathrm{~m}$ altitude and have a similar climate. Fig. 1 shows that roughly nine-tenths of the total rainfall of about $1100 \mathrm{~mm}$ falls during the wet season from November to April. Temperatures drop from around 22 to $16^{\circ} \mathrm{C}$ over the transition from the rains to the dry season.

The Zomba site is bounded on one side by a $2 \mathrm{~km}$ length of evergreen forest along the edge of which a series of six, evenly-spaced sampling sites (each of $<0.5$ ha) were visited in the first half of the study period. One of these peripheral sites (A) is a garden containing permanent bait traps while the others are centred on natural fruit falls (Ficus or Psidium spp.) at which the adult butterflies feed. The two main sampling sites (I and II) extended away from the middle of the forest-edge on either side of a small river which is fringed by dense forest. They are larger areas of lawns surrounded by shrubs and trees $(\mathrm{I}=3.75 \mathrm{ha} ; \mathrm{II}=2.25 \mathrm{ha})$. The study area at Blantyre consisted of secondary vegetation in a garden and surrounding abandoned fields. Larval food plants which consist of various species of grasses are seasonally abundant at all sites.

The general condition of the habitat was assessed once a week by eye. At Zomba, the greenness of the grasses was surveyed with reference to a $1 \mathrm{~m}$ square quadrat at two fixed points.

The butterflies. At least five species of Bicyclus co-exist at Zomba (Fig. 2; see Condamin, 1973). These are B.safitza (Hewitson), B.anynana (Butler), B.ena (Hewitson), B.vansoni Condamin and B.cottrelli (Van Son); a few specimens of B.angulosus (Butler) have also been taken at site A. Only the first three species were collected at Blantyre. The species are all small brown butterflies (wingspan $40-50 \mathrm{~mm}$ ) which fly at or 


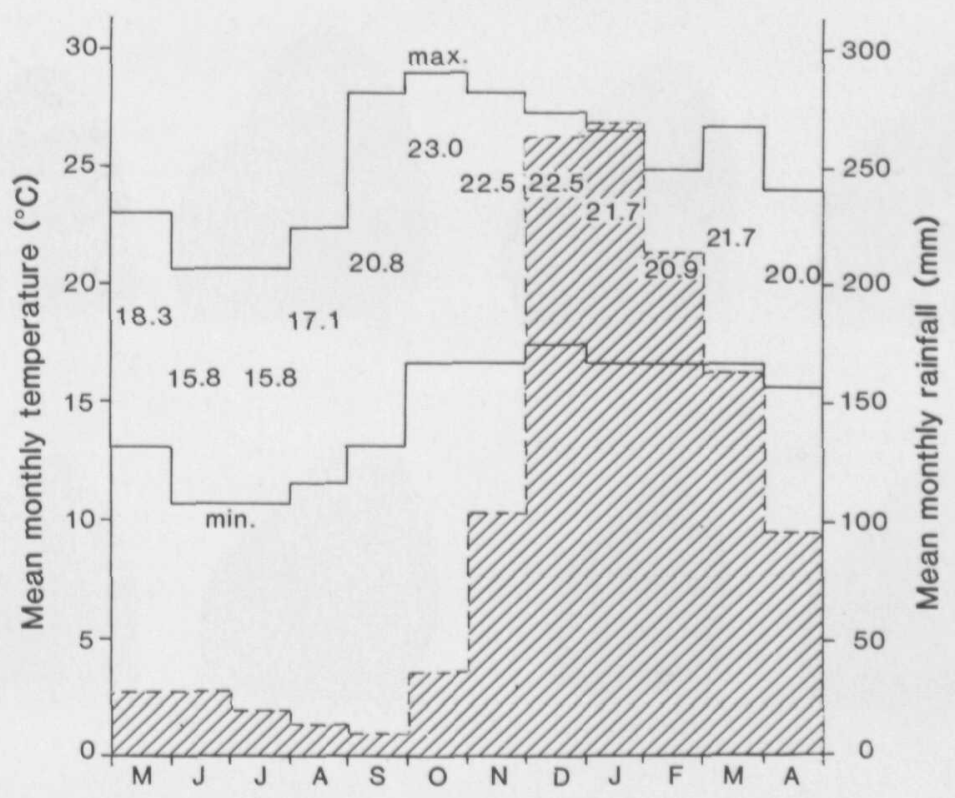

Fig. 1. The seasonal climate at Blantyre: monthly rainfall (hatched); maximum, minimum and average ([max. + min.]/2) temperatures. Source: National Atlas of Malawi, Malawi Government 1983.

close to ground level. This study focusses mainly on B.safitza, the most abundant species (about $70 \%$ of 1528 Bicyclus taken at I and II).

Scoring of phenotypic variation. B.safitza and B.anynana butterflies were scored at first capture for each of the three most important ventral wing pattern elements, using an ordinal scale ranging from extreme dry season to extreme wet season type; eyespots, the pale band and the marginal chevrons were scored on an 8-, $5-$, or 4-point scale, respectively. Such visual assessments are highly repeatable across scorers and also correspond very closely to results from computer-aided morphometric analyses (J. Windig, unpublished).

Wing wear (a 7-point scale from freshly emerged to worn) and symmetrical wing damage (reflecting unsuccessful predator attacks; see Bowers \& Wiernasz, 1979) were recorded at each capture, together with behavioural activities relating to crypsis and reproduction. The length of the forewing of every third butterfly was measured to $\pm 0.5 \mathrm{~mm}$.

Studies of reproductive maturity. Egg-laying was examined in net cages for twenty to thirty females of B.safitza collected at each study area in the first, middle and last weeks of the study period. In addition, abdomens of samples of about twenty females collected at different times were preserved in alcohol for later dissection.

Mark-release-recapture experiment. All new captures of B.safitza, except those trapped at site $\mathrm{A}$ or retained for dissection, were marked with unique numbers and then released at their point of capture. Initial data analysis indicated some departures from age-independent survival. Because of this and since recapture rates were high (see Table 1; numbers of recaptures made on day $i$ which were also caught before and after day $i$ usually exceed ten), estimates of population size were mainly obtained using Manly \& Parr's (1968) method.

The basic assumptions of capture-recapture models (see Begon, 1979) are met by our data. Neither marking $\left(\chi^{2}=49.23\right.$, d.f. $=41, P$ is NS) nor handling $\left(\chi^{2}=58.61\right.$, d.f. $=58, P$ is NS: independence of mark status) influenced mortality in a significant way. Leslie's (1958) test shows that sampling was random for the cohort of butterflies known to be alive between 24 May and 20 June $\left(\chi^{2}=31.15\right.$, d.f. $=27, P$ is NS). The sexes are equally catchable $\left(\chi^{2}=25.86\right.$, d.f. $=28, P$ is NS).

Small numbers of the dry season form of $B$. cottrelli were included in the marked cohorts of B.safitza at Zomba. These two species appear 

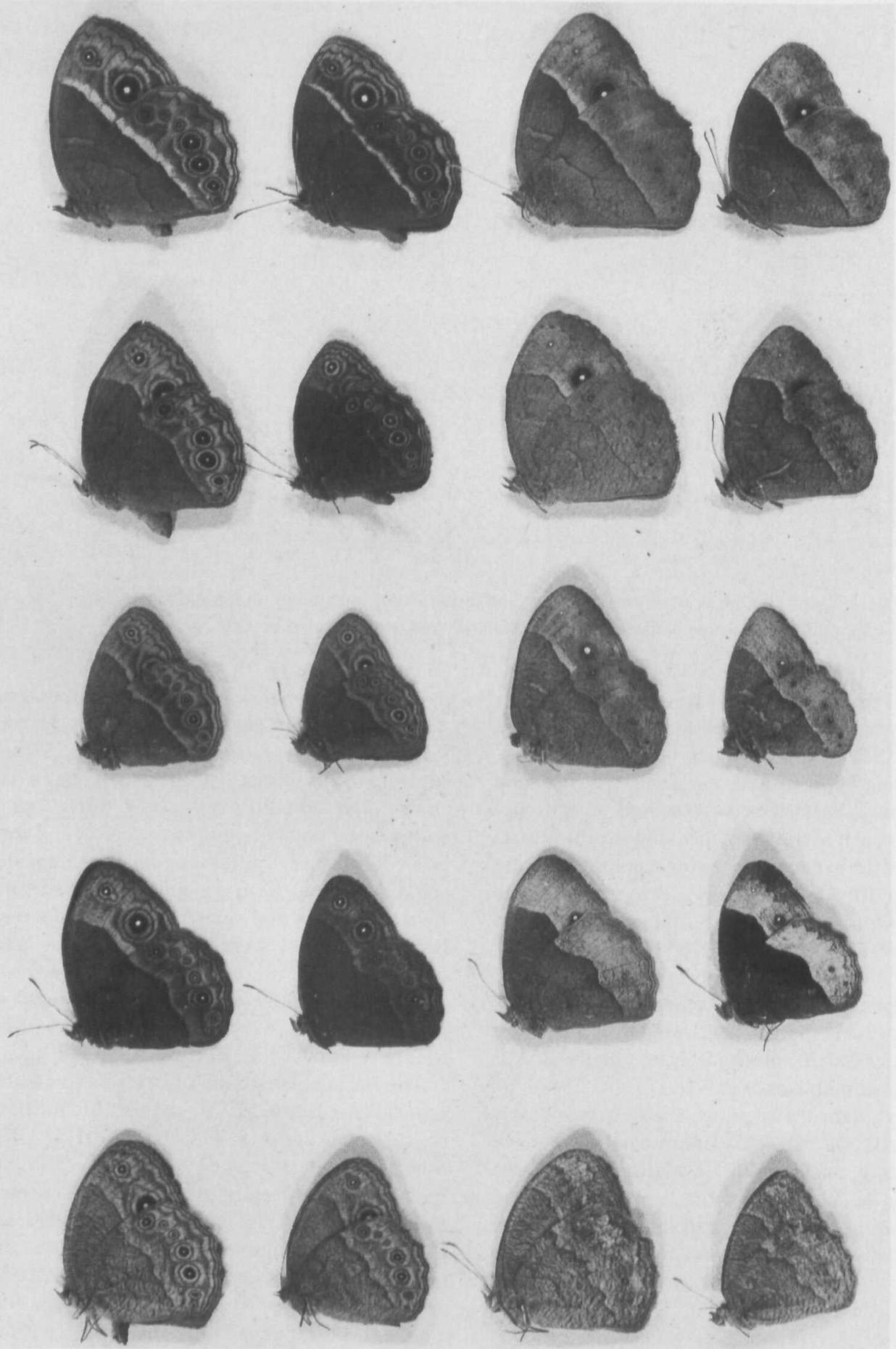

Fig. 2. The species of Bicyclus occurring at Zomba. The five rows in sequence from top to bottom correspond to the species: safitza, cottrelli, anynana, vansoni and ena. The columns from left to right show in sequence representative examples of the female wet season form, the male wet season form, the female dry season form and the male dry season form. The forewing length of the top left specimen is $28 \mathrm{~mm}$. 
to be very similar in the field with respect to size, wing pattern of the dry season form (see Fig. 2), ecology and behaviour. Since B.cottrelli is much less abundant than B.safitza (about $20 \%$ ), it is unlikely that any substantial bias will have been introduced into estimates of population parameters for B.safitza by this mis-classification.

Laboratory experiments. Environmental control of the phenotypic variation was studied using stocks of B.safitza and B.anynana established from about thirty females of each species collected in March 1987 at Blantyre. Breeding took place at $26 \pm 1{ }^{\circ} \mathrm{C}, 80-90 \%$ r.h. and $12: 12$ L:D; conditions comparable with the rainy season (see Fig. 1) and which produce the wet season form. Larvae were fed mainly on maize. Samples of freshly-moulted fifth (final) larval instars were reared at 29,23,20,17 and 14 $( \pm 1){ }^{\circ} \mathrm{C}$ with high r.h. and 12:12 L:D. Groups of two or three experimental caterpillars were kept in glass jars $(500 \mathrm{ml})$ with freshly-cut maize leaves. The position of jars within temperature cabinets was randomized and changed daily. Pupae were transferred to $26^{\circ} \mathrm{C}$ following weighing on the day after pupation. Ventral wing pattern elements of eclosed adults were scored on the same scales as in the field.

Wing pattern analysis. A summary description of the ventral wing pattern was made by using the first principal component (PC1) extracted from the correlation matrix of the three pattern elements. The variables are weighted similarly in the separate principal component analyses of the field and the laboratory data, and both groups of butterflies include the complete range in phenotype. This enables a direct comparison using PC1-scores of phenotypic changes in the field and the differences between the laboratory temperature treatments. PC1, accounting for $88 \%$ of the total variance, is the only meaningful component in each case (cf. Frontier, 1976). The PC1-scores are used to classify butterflies into four groups: the wet season form (wsf); the dry season form (dsf); and two intermediate classes (I1 and I2; the latter most resembles the dsf).

\section{Results \\ Correlated changes in butterflies and their environment}

Wet season form butterflies (wsf) were gradu- ally replaced by the dry season form (dsf) during the study period. The change over time of mean PC1-score describing the ventral wing pattern of first captures of B.safitza and B.anynana is shown in Fig. 3(a, b). A MANOVA for factors time, species, locality and sex shows that, except for sex, all main effects and their interactions are highly significant $(P<0.001)$. B.anynana at Blantyre showed an earlier replacement by the dsf than occurred in B.safitza. A less marked difference between the species at Zomba, as well as an earlier appearance of the dsf of B.safitza at Zomba than at Blantyre, may be artefacts of including the earlier appearing (in early May) dsf of B.cottrelli with B.safitza at Zomba (see Material and Methods; Fig. 3).

Some samples, especially in the middle of the study period, included many intermediates $(38 \%$ of the total of 1056 B.safitza at Zomba; see Fig. $3 c, d)$. An examination of the subset of PC1scores for B.safitza captured for the first time in very fresh condition at Zomba shows that here emergence of intermediates is restricted to the first 2 weeks of our study and possibly a short period before that. A period of a few weeks is short relative to the time-scale of climatic changes associated with the seasonal succession (see Fig. 1). Rather uniform dsf insects emerged during the following 6 weeks.

The turnover of the population of B.safitza at Zomba is supported by a decline in both the mean of weekly wing wear state (two-way ANOVA: $F=5.57$, d.f. $=7, P<0.001$; sexes do not differ significantly) and in its variance (ratio of first and last week's variances is 2.23, d.f. $=153,90 ; P<0.01$; our index of wing wear is closely related to age, see below and Fig. 7).

The change in relative frequency of the seasonal forms coincided with a drying-out ('browning') of the habitat (Fig. 4). The larval food plants, Oplismenus and Setaria grasses, dried out almost completely (increasing from about $50 \%$ to $>90 \%$ brown). The main grass of the lawns, Axonopus flexuosus (Peter), on which females were also observed to lay, retained some greenness throughout the study period because of a uniform, rather than a patchy, distribution of wilted leaves (increasing from about $30 \%$ to $65 \%$ brown). A carpet of dead brown leaves was produced underneath trees and shrubs (Fig. 4).

Butterflies in June and early July were significantly more likely to rest on dead leaves (Fig. 5; 

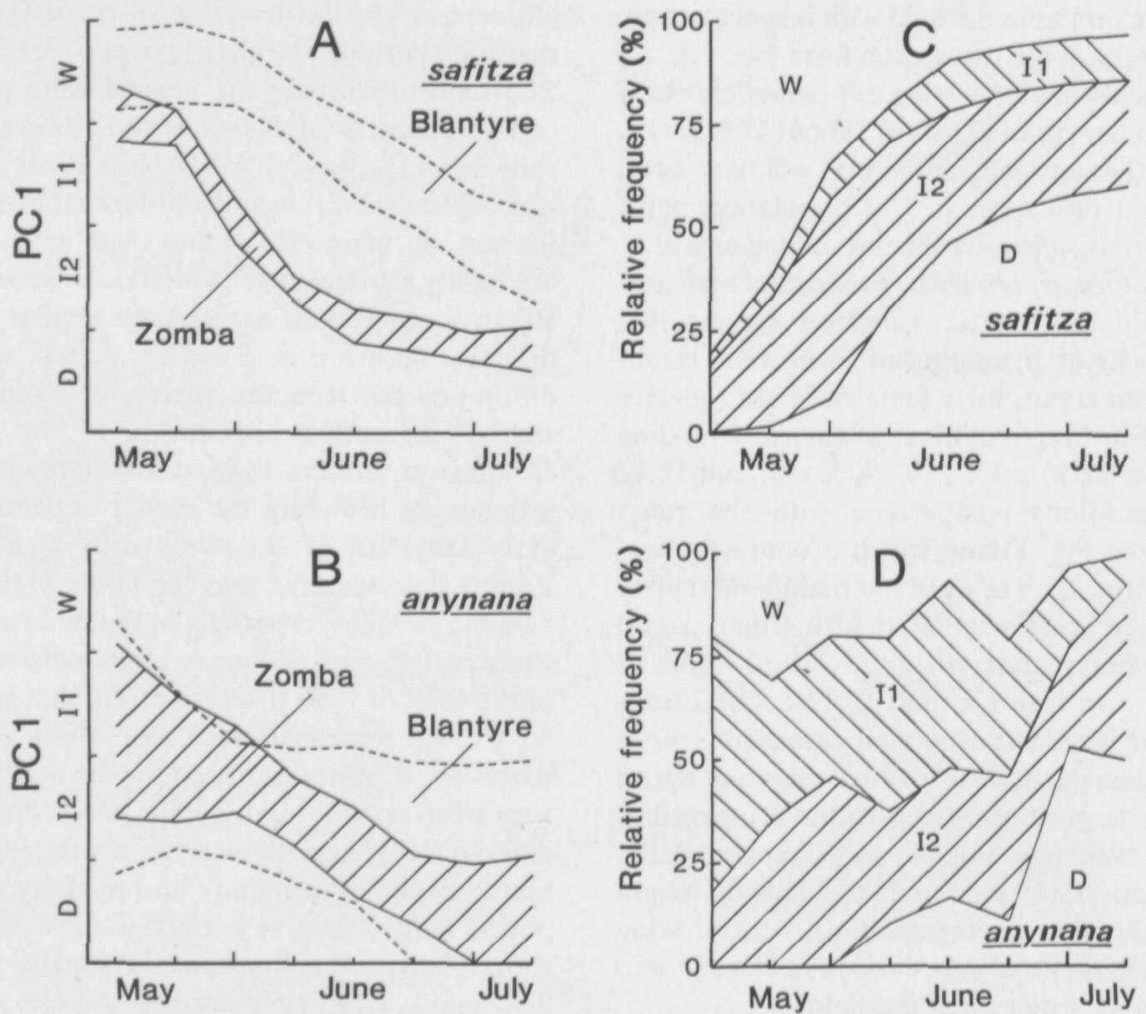

Fig. 3. Seasonal changes in the phenotype of Bicyclus safitza and B.anynana in two populations in Malawi over the transition from a wet to a dry season. The envelopes in A and B show $95 \%$ confidence intervals for weekly means for the first principal component describing wing pattern. Wet season form $=\mathrm{W}, \mathrm{dry}=\mathrm{D}$; intermediates $=$ I1 and I2. The relative frequencies of the phenotype classes are shown in C and D. Only data for butterflies on first capture at Zomba are analysed. Weekly sample sizes for B.safitza and B.anynana varied from 100 to 268 and from 10 to 46 , respectively.

$\chi^{2}=80$, d.f. $\left.=1, P \ll 0.001\right)$. Moreover, individuals of the dsf, in contrast to those of the wsf, were observed to perch preferentially on brown leaves including when these wère sparse (Fig. 5; compare resting behaviour of wsf and dsf-like intermediates in May). Dsf butterflies frequently screened (in 126 of 156 observations) the more prominent forewing eyespot (see Fig. 2 ), fully or for the greater part, by partial withdrawal between the hindwings immediately after perching. The wsf was never observed to show this behaviour. The dsf butterflies were also less active than the wsf, often staying in or near thickets. When approached they flew fast and straight (deeper) into the thicket or tried to hide underneath the leaves they were resting on, lying flat against them. On further disturb- ance and close probing the latter dsf butterflies would often continue to move into the leaf litter and not fly away.

Females taken into captivity in May immediately laid eggs, but oviposition was neither observed in captive nor in field females from the beginning of June. The final group of captive females (all dsf) when kept at high temperature and humidity in the laboratory, mated and began to lay eggs after a delay of 1-2 weeks. Males in early May frequently chase one another, often beginning with a circling display flight. These male-male interactions also ceased in the field in late May, but some chasing of females persisted through June.

The dissection of female abdomens shows that the proportion of butterflies with mature eggs 

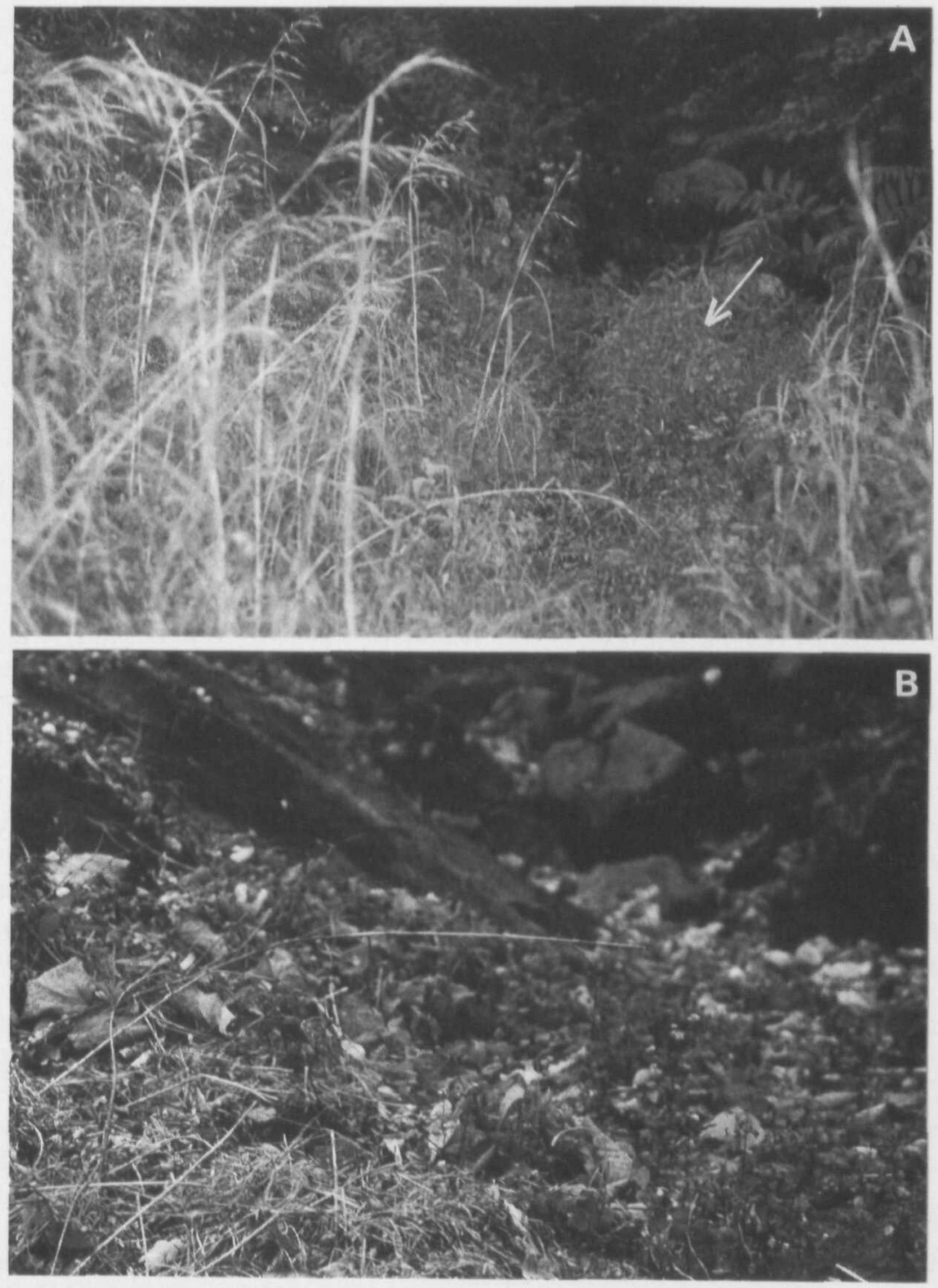

- Fig. 4. The seasonal change in biotope near ground level at one of the six peripheral sites at Zomba. Photographs A and B cover roughly the same area and were taken in late April and mid-September 1988, respectively. The thick layer of green herbage including grasses (food plants indicated by arrow) in the wet season (A) is replaced by a carpet of dead foliage, leaves or bare ground in the height of the dry season (B). (Photo B by courtesy of Dr H. Meredith.)

declined over the three samples taken in early May, mid-June and early July (Zomba: $94 \%$, $n=19 ; 33 \%, n=35 ; 39 \%, n=14$; Blantyre: $90 \%, n=10 ; 66 \%, n=16$; no sample for July). Furthermore, an increasing proportion of the females showed marked development of fat bodies. Inspection of females collected later in the dry season at site A failed to detect any mature eggs. The dissections also showed the presence of two spermatophores in a substantial proportion of mated females $(34 \%, n=29)$, indicating that females may mate more than once. 


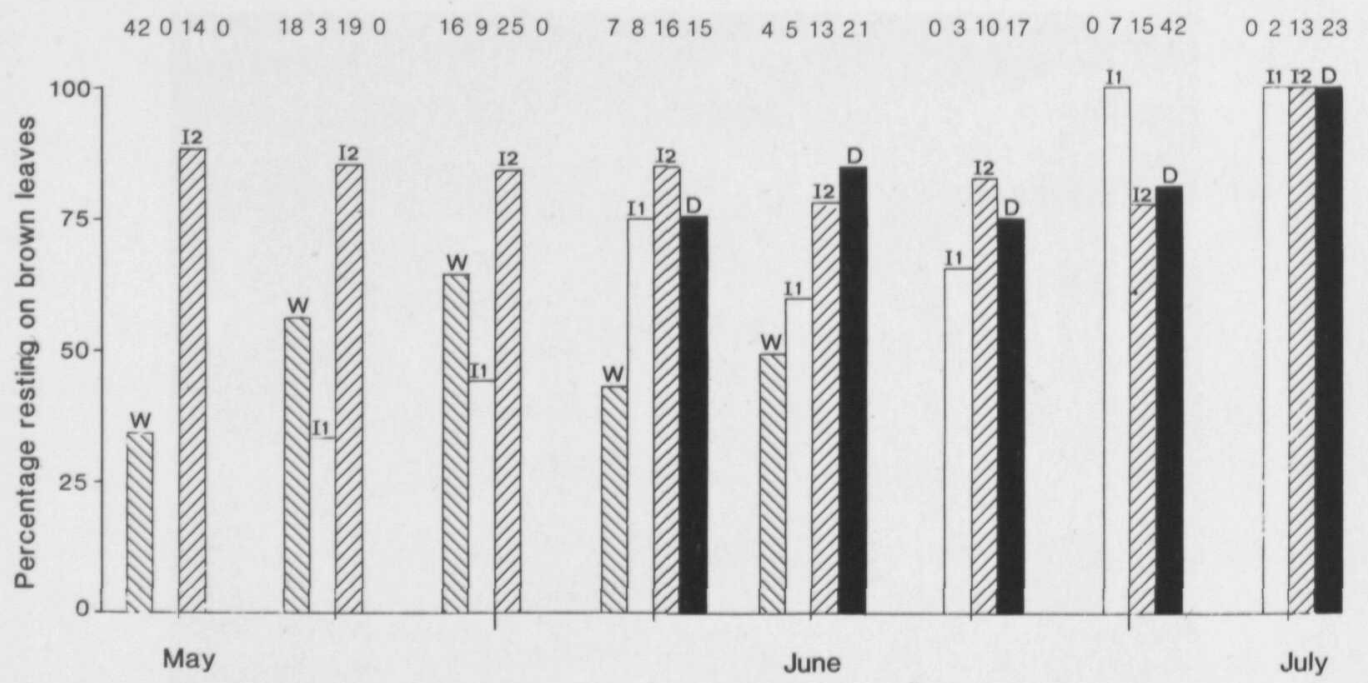

Fig. 5. Proportion of the seasonal forms of Bicyclus safitza (W= wet, $D=$ dry, $I 1$ and $I 2=$ intermediates) observed at rest on first sighting on dead brown, as against fresh green, leaves at Zomba during the transition from the wet to the dry season. Numbers above bars indicate sample sizes.

Females are larger than males (see Fig. 2). Butterflies of the dsf within each sex tended to be larger than those of the wsf at Blantyre $(P \ll$ $0.001 ; R^{2}$ against $\mathrm{PC} 1$-score $=0.36$; mis-classification of the smaller B.cottrelli dsf as B.safitza might have interfered with any similar trend at Zomba). In males, dsf butterflies also tend to be more variable in size (Zomba: $F=2.25$, d.f. $=55 ; 38, P<0.01$; Blantyre: $F=2.40$, d.f. $=23 ; 16, P<0.05$; females $=$ NS).

\section{Mark-release-recapture experiment}

Of the 869 B.safitza released in May and June at Zomba, 468 were recaptured at least once. Of these about two-thirds $(n=313)$ remained at their site of original release (see Table 1). Longer-distance movements by both males and females of each form towards Zomba's two main sites, I and II, were recorded from each of the six peripheral sites. Only two reverse movements were recorded. Immigration to sites I and II occurred more frequently in June than in May (Table 1). Females only exhibited such movement in June, that is, after the observed oviposition period. Many immigrants (eighteen of thirty-two) seemed to have settled at I and II since they were recaptured at least one more time. Observed recapture rates were higher in
June than in May (Table 1). These observations may be due to a general movement to wetter areas closer to the river as the habitat dries out in June. Territoriality may have also been reduced in males leading to more short movements between I and II (Table 1).

Estimates of population size show that density at sites I and II rose from less than thirty B.safitza butterflies per ha in May to a peak of seventy-five per ha in June. There is also evidence of a fall in early July, possibly in association with an increasingly quiescent behaviour.

Fig. 6 shows the survivorship curves for cohorts of wet and dry season forms (mean pattern expression in these cohorts was about $75 \%$ and $25 \%$, respectively, of the maximum; refer to Material and Methods). An increased rate of loss is evident after a variable period (10-30 days) of constant survivorship. The timing of the point of inflexion in the curve for wsf females coincides with the observed cessation of oviposition. Estimates of survival-rate indicate an expectation of life of about 1 month for the wsf, almost twice as long as for the dsf (Table 2). However, some dsf butterflies survive throughout the dry season to reproduce during the early rains in October. This has been confirmed by the recapture of six dsf butterflies at site A about 5-6 months after their first capture at 
Table 1. Numbers of Bicyclus safitza butterflies released and recaptured at Zomba together with the number of movements of long $(>500 \mathrm{~m})$ or short (between nearby sites) distance.

\begin{tabular}{|c|c|c|c|c|c|}
\hline \multirow[b]{2}{*}{$\begin{array}{l}\text { Sites of } \\
\text { release }\end{array}$} & \multirow[b]{2}{*}{ Period } & \multirow[b]{2}{*}{$\begin{array}{l}\text { No. of } \\
\text { releases }\end{array}$} & \multirow[b]{2}{*}{$\begin{array}{l}\text { No. }(\%) \\
\text { recaptured* }\end{array}$} & \multicolumn{2}{|c|}{ No. of movements } \\
\hline & & & & Short & Long \\
\hline \multicolumn{6}{|l|}{ Males } \\
\hline \multirow{3}{*}{ Central } & May & 189 & $69(36.5)$ & 6 & 2 \\
\hline & June & 245 & $166(67.8)$ & 65 & - \\
\hline & May-June & 464 & $265(57.1)$ & 85 & 2 \\
\hline \multirow{3}{*}{ Peripheral } & May & 93 & $12(12.9)$ & 2 & 7 \\
\hline & June & 0 & - & - & - \\
\hline & May-June & 93 & $29(31.2)$ & 2 & 24 \\
\hline \multicolumn{6}{|l|}{ Females } \\
\hline \multirow{3}{*}{ Central } & May & 128 & $57(44.5)$ & 15 & 0 \\
\hline & June & 130 & $87(66.9)$ & 15 & - \\
\hline & May-June & 272 & $160(58.8)$ & 44 & 0 \\
\hline \multirow{3}{*}{ Peripheral } & May & 40 & $6(15.0)$ & 0 & 0 \\
\hline & June & 0 & - & - & - \\
\hline & May-June & 40 & $14(35.0)$ & 0 & 8 \\
\hline
\end{tabular}

* Numbers of recaptures or of movements recorded during that month(s) plus the first week of the next month. All long movements occurred from the peripheral to the central (I and II) sites.

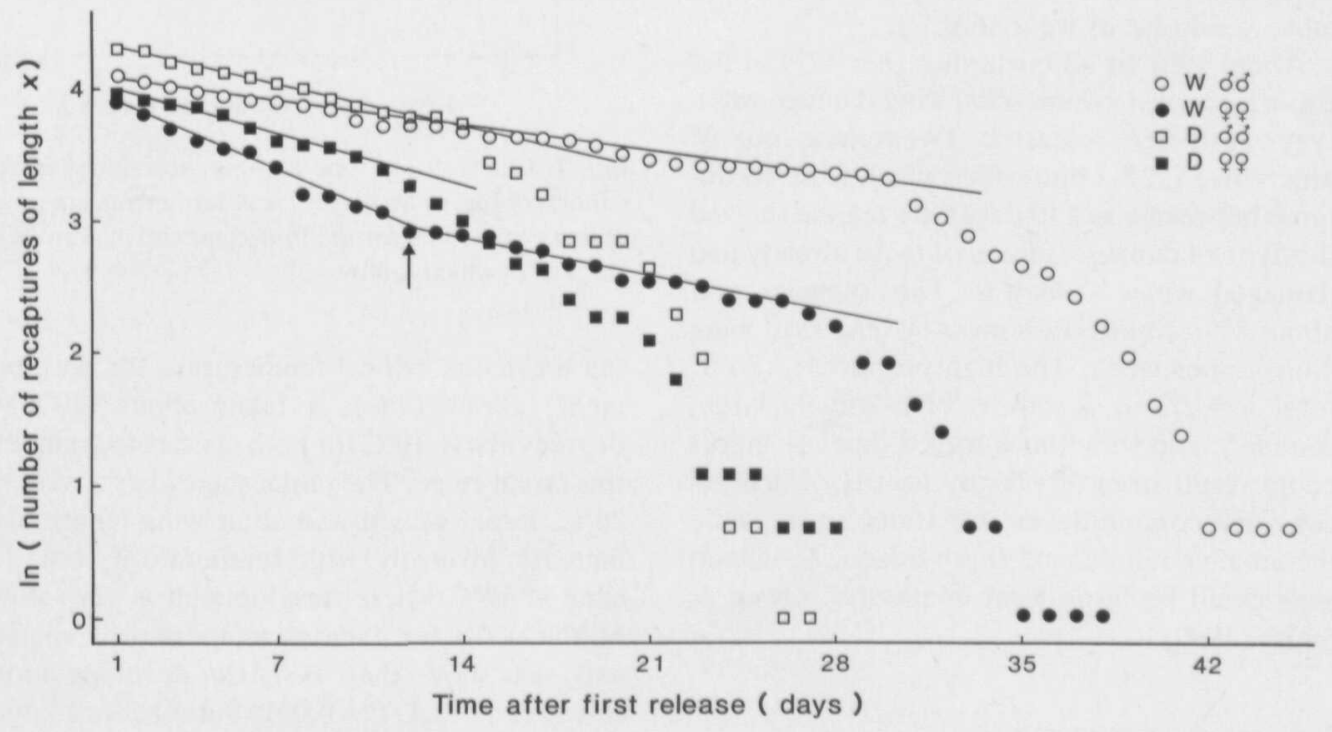

Fig. 6. Known length of life of cohorts of about 100 male or female Bicyclus safitza of the wet (W) and dry (D) season forms. The individuals of each cohort were initially released over a period of about 7 days (weeks $1-2$ for W and weeks 4-5 for D; see Fig. 3). Lines are fitted by eye for periods of constant initial survival. The point of inflexion in the line for $\mathrm{W}$ females as indicated by the arrow approximately coincides with the observed cessation of oviposition. 
Table 2. Estimates of $24 \mathrm{~h}$ survival-rate and expectation of life in days (given in parentheses) for the cohorts of Bicyclus safitza shown in Fig. 6 over the initial periods of constant survival.

\begin{tabular}{|c|c|c|c|c|}
\hline \multirow[t]{2}{*}{ Method } & \multicolumn{2}{|c|}{ Wet season form } & \multicolumn{2}{|c|}{ Dry season form } \\
\hline & Males & Females & Males & Females \\
\hline Seber* & $0.969(31.8)$ & $0.917(11.5) \dagger$ & $0.947(18.4)$ & $0.944(17.4)$ \\
\hline Fisher-Ford $\ddagger$ & $0.973(36.5)$ & $0.966(28.9)$ & $0.949(19.1)$ & $0.947(18.4)$ \\
\hline
\end{tabular}

* Seber's (1982) maximum-likelihood method.

$\dagger$ Immediately after the observed period of egg-laying, the estimate is 0.979 (47.3).

¥ Estimates for all males and all females released during the whole study period at sites I and II at Zomba (see Table 1) are $0.977(43.0)$ and $0.968(30.8)$, respectively.

sites I or II. Emigration or avoidance of capture is thus likely to contribute substantially to the estimates of survivorship, especially for the dsf. This is supported by a repartitioning of loss and gain (Jackson, 1939) using data for mid-June, which suggests that emigration and immigration are at least as important as mortality and birth.

Each of the cohorts from Fig. 6 showed a marked increase in wing wear with age (Fig. 7). Initially fairly fresh butterflies (code 3 ) became well-worn (code 4-6) within a month. The most active category, the wsf males, showed the most rapid rate of wear (Fig. 7).

About $10 \%$ of all butterflies $(n=423)$ in the cohorts showed symmetrical wing damage when they were first released. Twenty-one out of ninety-five $(22 \%)$ butterflies which were recaptured between 4 and 10 days after release showed this type of damage; fifteen of these already had damaged wings at day 0 . This suggests that about $8 \%$ of butterflies incur symmetrical wing damage per week. The high proportion $(86 \%$, total $n=152$ in B.safitza) of relatively large, rounded, and sometimes frayed damage marks could result from attacks by lizards, which occur very commonly at the study sites, while the smaller number of sharp-edged, V-shaped gaps could be birds' beak marks (cf. Owen \& Smith, 1990).

\section{Laboratory experiments}

Development time of fifth larval instars increased with decreasing rearing temperature as a negative exponential function, ranging from 10 days or less at $29^{\circ} \mathrm{C}$ to about 30 days at $14^{\circ} \mathrm{C}$ $\left(R^{2}=0.75\right)$. This implies that metabolic rate depends linearly on the temperature excess over

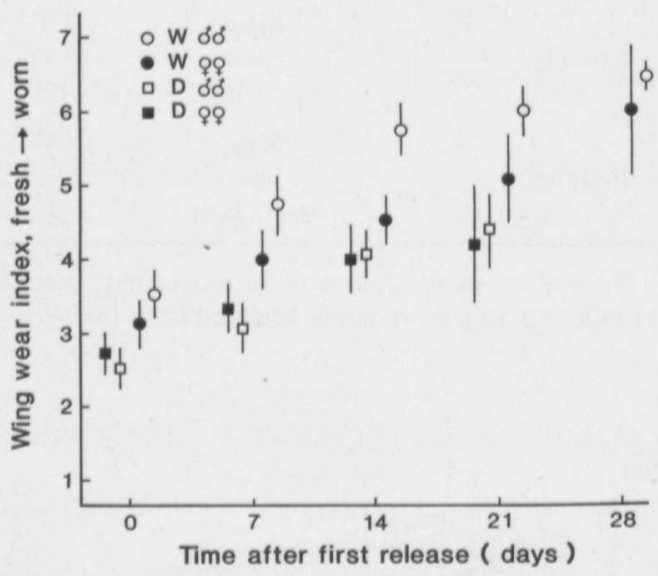

Fig. 7. Change over time in wing wear index in the cohorts of Fig. 6. Means \pm 2 standard errors are given at first release and for the four consecutive periods of $7 \pm 3$ days which follow.

the estimated critical temperature for development (about $10^{\circ} \mathrm{C}$ ); it takes about 140 daydegrees above $10^{\circ} \mathrm{C}$ for both species to complete this larval stage. The pupal stage lasts a week at $26^{\circ} \mathrm{C}$. Pupal weight and adult wing length also increase inversely with temperature, but decline at $14^{\circ} \mathrm{C}$ where development is very slow. MANOVAs for factors temperature, species and sex show that B.safitza develops more slowly $(F=40.4, P \ll 0.001)$ but reaches a larger size than B.anynana $(F=147.0, P \ll 0.001)$; as in the field (see Fig. 2), the sexual dimorphism in size is more pronounced in B.anynana (species $X$ sex interaction: $F=28.4, P \ll 0.001$ ). Reared butterflies were markedly smaller than wild ones, indicating that our rearing conditions were not optimal. 


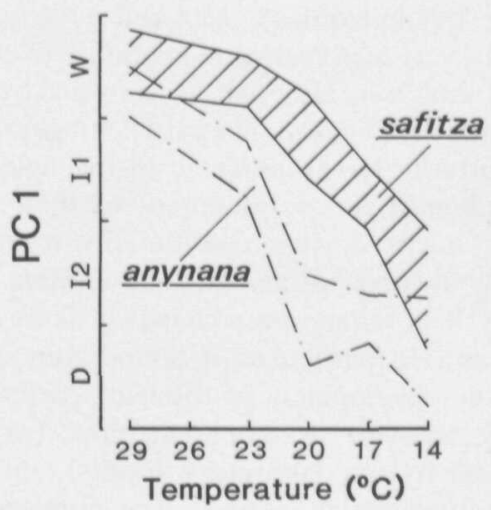

Fig. 8. The effect of temperature during the final instar in laboratory experiments on Bicyclus safitza and B.anynana. The envelopes show $95 \%$ confidence intervals for treatment means for the first principal component describing wing pattern (wet season form $=W$, dry $=D$; intermediates $=$ I1 and I2). Sample sizes at each temperature are about thirty in both sexes.

Fig. 8 shows that lower temperatures in each species induce progressively more extreme dry season phenotypes. There is thus a general correspondence with the field (Fig. 3) where temperatures decline over the seasonal transition (Fig. 1). However, there are differences in detail since the dsf of $B$.safitza tends to be less extreme in the laboratory, as does the wsf of B.anynana. In both the field and the laboratory, the species, but not the sexes, were out of phase.

There is a strong correlation between the duration of the final larval instar and PC1-score $(r=-0.62, P \ll 0.001$ in B.safitza). The correlation is also significant within temperature treatments. The partial correlation coefficient (temperature is held constant) is higher than that for temperature and PC1-score $(r=-0.42$ and 0.29 ). These results suggest that development time rather than temperature per se may be the fundamental factor controlling phenotypic plasticity.

\section{Discussion}

Populations of Bicyclus species in Malawi show a turnover at the interface between the annual wet and dry seasons. Butterflies with a conspicuous ventral wing pattern are replaced by more uniformly-coloured individuals. The seasonal polyphenism involves the eyespots, the submarginal chevrons and, in some species, the pale band (Fig. 2). The correlations among these pattern elements are about 0.8 in both B.safitza and B.anynana, so the level of phenotypic integration (Schlichting, 1986) is high. Except for B.ena which has marbled grey wings in both seasons and is more associated with rocky substrates, the background colour also differs between the seasonal phenotypes of each species (Fig. 2). The dsf's of B.safitza, the very similar B.cottrelli, and B.vansoni usually rest on dead leaves which they closely resemble. At our study sites dsf B.anynana seemed to be more restricted to patches of bamboos; their coloration blends with fallen strips of yellow bamboo on reddish clay. The paler outer area of the wings characteristic of the dsf males of B.vansoni and B.anynana (see Fig. 2), and to some extent of B.safitza and B.cottrelli, may enhance their crypsis; males are more likely to occur in areas of transition from sun to shade.

Our finding of a considerable proportion of butterflies with symmetrical wing damage is consistent with the importance of attacks by visuallyhunting predators. The effectiveness of crypsis of butterflies at rest is likely to be paramount in survival to the beginning of the rains when larval foodplants regenerate. Survival of some dsf butterflies (as reproductively inactive adults) throughout the dry season is confirmed by the recaptures of marked specimens at site A in Zomba. A new generation of wsf butterflies does not appear until late December some weeks after the rains begin (see Fig. 1). This is followed by a further generation of the wsf in the mid-late rains.

The phenotypic changes are part of an array of coordinated traits which include behavioural and life history components (see also Tauber et al., 1986; Brakefield, 1987). The data on wing size are consistent with the life cycle scenario for polyphenic butterflies in highly seasonal environments outlined by Brakefield (1987). A larger as well as more variable size in the dsf might be the result of opportunistic development at the end of the wet season. The wsf, on the other hand, will derive more benefit from fast development (leading to smaller size) which enables their progeny to complete development before the biotope dries out. Our field observations indicate differences in behaviour and activity between the forms. It would be interesting to determine using bred butterflies whether such 
differences persist when both forms are flying in the same environment.

Intermediates are common during the wet to dry seasonal succession. In the rainy season intermediates are very infrequent at site A (unpubl. data) while in the dry season most are similar in appearance to the dsf. Our laboratory experiment produced the complete range in phenotype, including many intermediates close to the wsf in appearance at $20^{\circ} \mathrm{C}$ (see Fig. 8). Thus the plasticity system is quite strongly canalized in the field to usually produce either the wsf or butterflies with little or no development of the pattern elements.

B.safitza is quite sedentary in its movement, tending to remain within a single habitat patch. The data on movement and reproductive maturity suggest that many dsf butterflies in June and July move to dense thickets where they aestivate inactively. Trapping data at site $\mathrm{A}$ also indicate low activity during the height of the dry season. Estimates of density increased between May and June reaching 200 butterflies per ha at Blantyre. Here, in less open and more secondary biotope the species' density was about 3 times higher than at Zomba. The occurrence of only B.safitza, B.anynana and B.ena at Blantyre might also reflect the secondary nature of the biotope; B. vansoni, in particular, is more strictly limited to a forest biotope.

Estimates of survival-rate are closely similar across localities. Moderate standard errors ( $c$. 0.1 ) for Jolly's estimates and the differences in phenology mean that it is not possible here to compare the survival-rate of the seasonal forms. We plan to examine the consequences of the predicted differences in crypsis between the forms by comparing the survival-rate of cohorts of each form released at the same time in each season when the local population is predominantly of either one form or the other.

Although the range of rearing temperatures exceeded that of mean monthly temperatures in the field, few B.safitza of the extreme dsf phenotype common in the field, and few B.anynana of the extreme wsf, were reared. Preliminary experiments indicate that relative humidity also has a significant effect on the plasticity but one much smaller than temperature, and that extension of the temperature treatment to include earlier larval instars increases the phenotypic range in adults (unpubl. data). However, in a similar experiment with the African Precis octavia (Nymphalidae), McLeod (1968) also needed a very high rearing temperature to obtain the extreme wsf, although larvae were treated from the second instar. The actual temperatures that butterfly larvae perceive in the field and that influence the development of their wing pattern might deviate considerably from the monthly averages of maxima and minima. The daily cycle of temperature change is likely to be important. In particular, if temperature influences the development of the wing pattern indirectly through development time (as was suggested by our laboratory results), the low temperatures which occur at clear nights at the beginning of the dry season might explain the fact that the phenotypic response is much faster than the changes in average field temperatures as shown in Fig. 1. Poor food quality effects in the larvae at this time of year may have similar consequences.

The Bicyclus community in Malawi presents an interesting system for studies of the evolution of phenotypic plasticity. We aim to investigate how natural selection has influenced this system of an environmentally-induced phenotypic response which differs among species within localities and probably also among localities within species.

\section{Acknowledgments}

We would like to thank the many friends in Malawi who have helped greatly to make this research possible. In particular, we thank Cornell Dudley and John Wilson for their invaluable assistance. Rinny E. Kooi, Hans Roskam and Jack Windig made helpful comments on an earlier draft of this paper. We are also most grateful to the Melchior Treub Trust for their financial support.

\section{References}

Begon, M. (1979) Investigating Animal Abundance: capture-recapture for biologists. Edward Arnold, London.

Bowers, M.D. \& Wiernasz, D.C. (1979) Avian predation on the palatable butterfly, Cercyonis pegala (Nymphalidae). Ecological Entomology, 4, 205-209.

Brakefield, P.M. (1987) Tropical dry and wet 
season polyphenism in the butterfly Melanitis leda (Satyridae): phenotypic plasticity and climatic correlates. Biological Journal of the Linnean Society, 31, 175-191.

Brakefield, P.M. \& Larsen, T.B. (1984) The evolutionary significance of dry and wet season forms in some tropical butterflies. Biological Journal of the Linnean Society, 22, 1-12.

Condamin, M. (1973) Monographie du genre Bicyclus (Lepidoptera Satyridae). Memoires de l'Institut Fondamental d'A frique Noire, no 88. Ifan-Dakar.

Dingle, H. (1982) Function of migration in the seasonal synchronization of insects. Entomologia Experimentalis et Applicata, 31, 36-48.

Frontier, S. (1976) Étude de la décroissance de valeurs propres dans une analyse en composantes principales: comparaison avec le modèle du bâton brisé. Journal Expérimental de la Biologie et Ecologie Maritime, 25, 67-75.

Gatehouse, A.G. (1989) Genes, environment, and insect flight. Insect Flight (ed: by G. J. Goldsworthy and C. H. Wheeler), pp. 115-138. CRC Press, Boca Raton, Florida.

Jackson, C.H.N. (1939) The analysis of an animal population. Journal of Animal Ecology, 8, 238-246.

Leslie, P.H. (1958) Statistical appendix. Journal of Animal Ecology, 27, 84-86.

Manly, B.F.J. \& Parr, M.J. (1968) A new method of estimating population size, survivorship, and birth- rate from capture-recapture data. Transactions of the Society for British Entomology, 18, 81-89.

McLeod, L. (1968) Controlled environment experiments with Precis octavia Cram. (Nymphalidae). Journal of Research on the Lepidoptera, 7, 1-18.

Owen, D.F. (1980) Camouflage and Mimicry. Oxford University Press.

Owen, D.F. \& Smith, D.A.S. (1990) Interpopulation variation and selective predation in the meadow brown butterfly, Maniola jurtina (L.) (Lepidoptera: Satyridae) in the Canary Islands. Biological Journal of the Linnean Society, 39, 251-267.

Schlichting, C.D. (1986) The evolution of phenotypic plasticity in plants. Annual Review of Ecology and Systematics, 17, 667-693.

Seber, G.A.F. (1982) The Estimation of Animal Abundance and Related Parameters, 2nd edn. Charles Griffin, London.

Shapiro, A.M. (1976) Seasonal polyphenism. Evolutionary Biology, 9, 259-333.

Slansky, F. (1982) Insect nutrition: an adaptationist's perspective. The Florida Entomologist, 65, 45-71.

Tauber, M.J., Tauber C.A. \& Masaki, S. (1986) Seasonal Adaptations of Insects. Oxford University Press.

Wolda, H. (1988) Insect seasonality: why? Annual Review of Ecolology and Systematics, 19, 1-18.

Accepted 17 November 1990 